\title{
Organization of Receptive Fields of Cricket Giant Interneurons Revealed by Cercal Ablations
}

\author{
Tetsuya Matsuura ${ }^{1,3}$ and Masamichi Kanou ${ }^{2 *}$ \\ ${ }^{1}$ Department of Biology, Faculty of Science, Okayama University, Okayama, Japan \\ ${ }^{2}$ Department of Biology and Earth Sciences, Faculty of Science, \\ Ehime University, Matsuyama, Japan
}

\begin{abstract}
In order to determine the contribution of each cercus and its receptors in organizing the receptive field of four air-motion sensitive giant interneurons (Gls 8-1, 9-1, 9-2 and 9-3) of the cricket Gryllus bimaculatus, effects of removing the ipsilateral or contralateral cercus (referred to the side of the axons) on specific parameters of the wind-evoked responses of these neurons were investigated. All 4 Gls received only excitatory inputs from a group of filiform hairs on the ipsilateral cercus. In addition to the ipsilateral excitatory inputs, Gls 8-1 and 9-1 received weak excitatory and strong inhibitory inputs from a group of filiform hairs on the contralateral cercus. Gl 9-2 received only inhibitory inputs from filiform hairs on the contralateral cercus. GI 9-3 received excitatory inputs from filiform hairs on the contralateral cercus and no inhibitory input was confirmed. In addition to such simple excitatory and inhibitory connections, the rebound motion of cercal filiform hairs had some role in organizing the receptive fields of Gls 9-2 and 9-3. Furthermore, the possibility of using a rebound depolarization of the membrane potential for mediating the long latency response in Gls $8-1$ and $9-2$ will be discussed.
\end{abstract}

\section{INTRODUCTION}

A large number of wind sensitive filiform hairs exist on the cerci of crickets. They are responsible for a wind-evoked escape behavior of the insects (Bentley, 1975; Gras and Hörner, 1992; Kanou et al., 1995). As giant interneurons (Gls) in the ventral nerve cord of crickets integrate the wind information from those cercal filiform hairs (Edwards and Palka, 1974; Tobias and Murphey, 1979; Kanou and Shimozawa, 1984), they are supposed to play a significant role in activating leg motoneurons (Kanou and Shimozawa, 1985) and mediating a wind-evoked escape behavior. Such wind-evoked escape behavior is highly directional, i.e. the insects almost always turn away from the stimulus source (Gras and Hörner, 1992; Kanou et al., 1995). Directional characteristics of Gls (Kanou, 1991, 1996; Levine and Murphey, 1980; Tobias and Murphey, 1979) must underlie such directional behaviors.

As information from cercal filiform hairs are main inputs to Gls, many studies have been focused on the physiological and mechanical features of the hair sensilla (Edwards and Palka, 1974; Gnatzy and Tautz, 1980; Kanou et al., 1988, 1989; Shimozawa and Kanou, 1984a, b). Traditionally, cercal filiform hairs have been classified into 2 major populations on

\footnotetext{
* Corresponding author: Tel. +81-89-927-9631; FAX. +81-89-927-8909.

${ }^{3}$ Present address: Akita Laboratory, Japan Science and Technology Corporation, c/o Akita Research Institute of Brain and Blood Vessels, 6-10, Senshu-Kubota machi, Akita 010, Japan.
}

the bases of their preferential plane for vibration; i.e. L-hairs (preferentially vibrate parallel to the longitudinal axis of a cercus) and T-hairs (preferentially vibrate parallel to the transverse axis of a cercus). They are further divided into two subpopulations from their directional sensitivities, i.e. anterior and posterior L-hairs, and lateral and medial T-hairs (Bacon and Murphey, 1984; Tobias and Murphey, 1979). Therefore, most studies dealing with the directional sensitivities of cricket Gls have been focused on the innervation with the 4 types of cercal filiform hairs (Bodnar et al., 1991; Jacobs et al., 1986; Levine and Murphey, 1980; Tobias and Murphey, 1979). However, it has been reported that obliquely oriented hairs exist in Acheta domesticus (Walthall and Murphey, 1986; Shepherd et al., 1988), and a recent study proved that the hairs can be divided into at least 8 subclasses (Landolfa and Jacobs, 1995). Although such detailed classification of cercal filiform hairs in Gryllus bimaculatus has not been as well confirmed as in Acheta, it has been reported that Gryllus is also equipped with D (diagonal) hairs other than L- and T-hairs (Gnatzy and Tautz, 1980).

Due to the variety of preferential directions in cercal filiform hairs, the receptive field of each $\mathrm{Gl}$ in Gryllus bimaculatus must be complicated. The aim of the present study was to explore the receptive field organization of each $\mathrm{Gl}$ in Gryllus bimaculatus by investigating the directional sensitivity of Gls after the unilateral cercal ablations. This process is essential for understanding the pattern of connection between a paticular GI and cercal filiform hairs with specific directionalities. More- 
over, such detailed investigation is also essential for the basis of more complicated studies of the neural network, e.g. an investigation of plastic natures (Matsuura and Kanou, 1998).

\section{MATERIALS AND METHODS}

\section{Animals}

Adult female crickets (Gryllus bimaculatus) reared in our laboratory were used. They were 1-2 weeks old after imaginal molt. The temperature of the culture room was kept at $28-30^{\circ} \mathrm{C}$ and the LD cycle was $14: 10$. Details were the same as in the previous paper (Kanou, 1996).

\section{Air current stimulation}

In the course of neurophysiological experiments, a unidirectional air current stimulus was given to a cricket in a wind-tunnel consisting of a pair of push-pull driven loud speakers (Kanou and Shimozawa, 1984). An electrical signal of a half cycle cosine wave was fed to the speakers so as to make a unidirectional air current in the tunnel. The frequency of the air-motion (although a whole cycle of cosine wave was not used, we use a term of "frequency" in order to express the rate of air-molecule displacement; ref. Kanou, 1996) was fixed at 50 $\mathrm{Hz}$ in all the experiments. The stimulus duration was, therefore, 10 msec (the time of a half cycle of $50 \mathrm{~Hz}$ ). Experimental setups and stimulating methods are the same as in the previous studies (Kanou, 1991, 1996).

Air current velocities employed in the present experiments ranged from $0.095 \mathrm{~mm} / \mathrm{sec}$ to $300 \mathrm{~mm} / \mathrm{sec}$. As the wind-tunnel could be rotated around the specimen in the horizontal plane, the direction of a stimulus air current could be changed even in the course of intracellular recordings. In the present study, air current stimuli were presented from 12 different directions ( $30^{\circ}$ intervals) (ref. Fig. 1A). At each stimulus direction, 10 successive air current stimuli with a particular peak velocity were applied to an insect at 5-second intervals. An averaged response magnitude (number of action potentials) and an averaged response latency of the 10 trials were calculated. The same measuring procedure was repeated at every $10 \mathrm{~dB}$ of the peak velocity of the stimulus air current. The averaged values were again averaged over the number of animals used. In order to avoid habituation, a weak stimulus was applied first, then the intensity (peak velocity of a stimulus air current) was increased stepwise.

\section{Neural activity recordings}

Activities of Gls were intracellularly recorded from axons in the right side connective at the point where it just left the 5th (terminal) abdominal ganglion. Recorded signals were fed into a microelectorode amplifier (Nihon Kohden; MEZ-8201) and displayed on a CRT (Tektronix; R5111A). Neural responses were stored on a magnetic tape (Maxell; DAT R-120DM) by a data recorder (TEAC; RD-111T) for the off-line analysis.

After the physiological investigation, Lucifer Yellow $\mathrm{CH}$, which was placed in glass microelectrode beforehand, was iontophoretically injected into Gls with $\pm 10 \mathrm{nA}$ square pulses for more than 5 min for morphological identification. After the dye injection, the specimen was incubated in a refrigerator for about $1 \mathrm{hr}$ before the observation.

Velocity thresholds (the lowest peak velocity of an air current that could elicit one action potential on a Gl) were obtained by an interpolation of the intensity response curves. For each response property such as velocity threshold, response magnitude or response latency, significance of difference between the intact and the ablated animals were statistically examined with the t-test.

\section{Ablation experiments}

A cercus of a cricket was removed from the stump with a sharp razor blade. Special attention was paid so as to remove all the mechanoreceptive cercal filiform hairs at the basal part of a cercus.
Neurophysiological experiments on the unilaterally cercal ablated animals were carried out within 1 day $(24 \pm 5 \mathrm{hr})$ after the treatment. As the ventral nerve cords which contain Gls' axons are on the contralateral side of their somata, we defined "ipsilateral" or "contralateral" referred to the side of axons. For example, "ipsilateral cercus" means the cercus which is at the same side of the axon of a Gl. As we made neural recordings from a right side connective, right cercus ablated crickets were called $\mathrm{CCl}$ (contralateral cercus intact) animals. In the same way, contralateral cercus ablated crickets were called ICI (ipsilateral cercus intact) animals. Normal intact crickets were called $\mathrm{BCl}$ (both cerci intact) animals.

\section{RESULTS}

An intensity-response relation of each Gl was measured by using a unidirectional air current stimulus. Results were compared to those from animals with both cerci intact $(\mathrm{BCl})$ (Kanou, 1996) in order to specify the role of ipsilateral and contralateral cercal inputs in organizing the receptive field of each GI (Fig. 1). Difference in response magnitudes between $\mathrm{BCl}$ and unilaterally cercal ablated animals $(\mathrm{ICl}$ or $\mathrm{CCl}$ ) will show the amount of excitatory or inhibitory inputs from filiform hairs on the ablated cercus. Response latencies of Gls were measured in $\mathrm{BCl}$ animals and were also compared to those measured in either $\mathrm{ICl}$ or $\mathrm{CCl}$ animals. These were the clues to estimate the number of synaptic connections and to reveal other response properties of a GI such as "hair rebound".

\section{Response properties of GI 8-1 in ICl animals}

GI 8-1 in ICl animals showed excitatory responses regardless of the directions of a stimulus air current (Fig. 2). This suggests that all types of filiform hairs on the ipsilateral cercus have excitatory connections with the Gl regardless of their directional sensitivities (Fig. 4, right). When a stimulus air current was applied from R60 direction, response magnitudes of GI 8-1 in ICl animals were significantly smaller than those in $\mathrm{BCl}$ animals $(\mathrm{P}<0.05$; Fig. 2$)$. This suggests that the contralateral filiform hairs sensitive to the R60 air currents have excitatory connection with GI 8-1 (Fig. 4, left). On the other hand, response magnitudes of $\mathrm{Gl} 8-1$ in $\mathrm{ICl}$ animals were larger than those in $\mathrm{BCl}$ animals when the air currents were applied from L90, L60, L30, 0, R30, R120, R150, 180 and L150 directions (differences were statistically significant other than L60: Fig. 2). This suggests that the contralateral filiform hairs activated by those air currents have inhibitory connection with the GI (Fig. 4, left). Thresholds for the inhibition seemed to be higher than those for excitations in most cases, because most of the thresholds were not largely affected by the contralateral cercal ablation (Fig. 1A).

In $\mathrm{BCl}$ animals, response latencies of GI 8-1 changed depending upon both intensity and direction of a stimulus air current (Fig. 3). In most cases, response latencies of the GI became shorter with the increase of stimulus velocity. Response latencies of the GI were relatively long to the air currents from the contralateral-front directions. In $\mathrm{ICl}$ animals, some of the response latencies of GI 8-1 to the air currents from 0, R150 and L90 directions were significantly shorter than those in $\mathrm{BCl}$ animals $(\mathrm{P}<0.05)$. As the contralateral filiform 

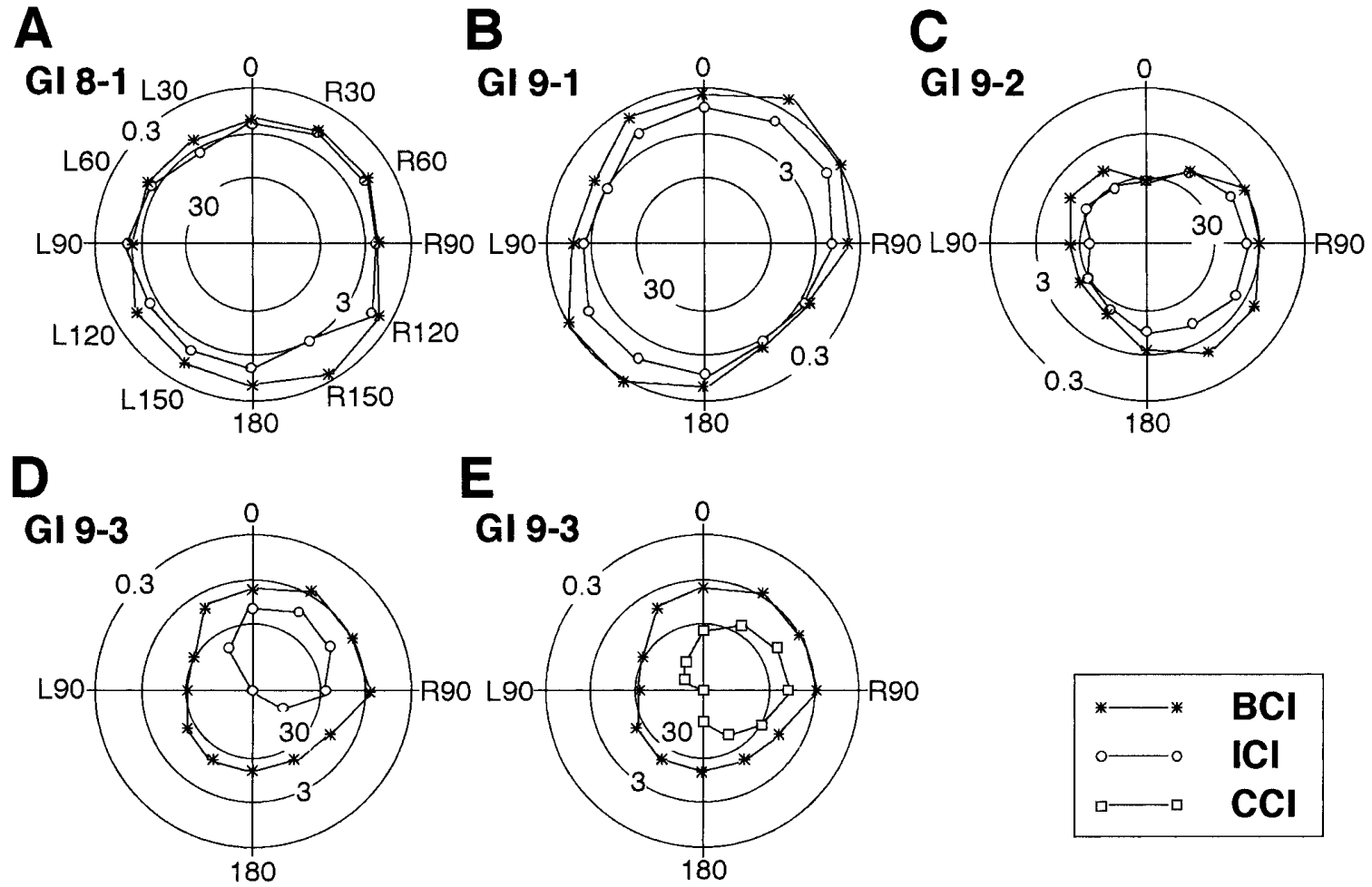

Fig. 1A-E. Receptive fields of 4 Gls running their axons in the right side ventral nerve cord. Velocity thresholds ( $\mathrm{mm} / \mathrm{sec}$ ) of the Gls to an air current from 12 different directions were plotted on the polar coordinates. (A) GI 8-1. (B) GI 9-1. (C) GI 9-2. (D) and (E) GI 9-3. Crosses: BCl animals (data from Kanou, 1996). Open circles: ICl animals within 1 day after the cercal ablation. Open squares: $\mathrm{CCl}$ animals within 1 day after the cercal ablation. Responses of Gls 8-1, 9-1 and 9-2 in CCl animals were very small or nothing at all. Note that the most sensitive directions of all the Gls in unilaterally cercal ablated animals were almost the same with those in $\mathrm{BCl}$ animals.

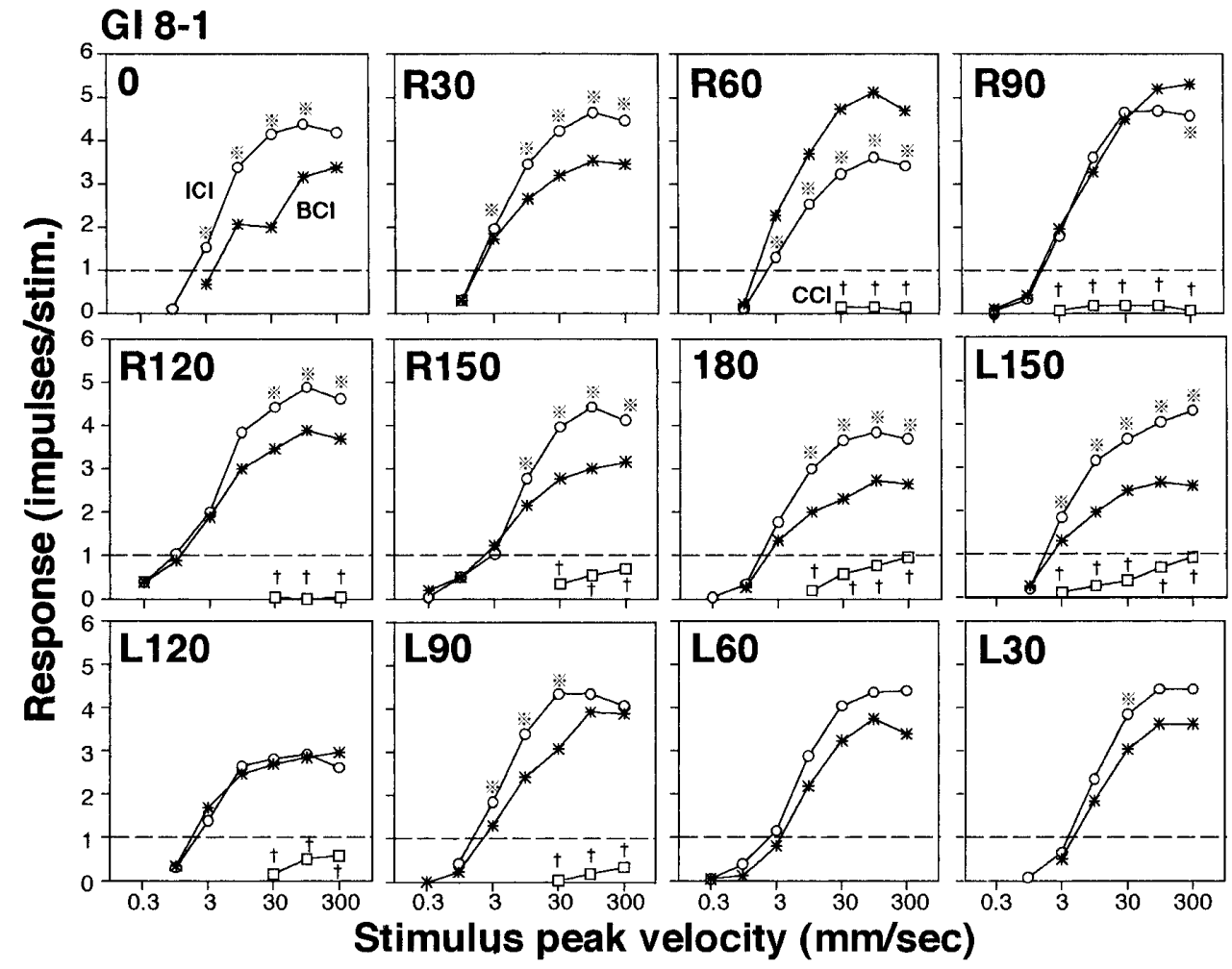

Fig. 2. Intensity-response curves of Gl 8-1 measured with a unidirectional air current from 12 different directions. Response magnitudes (averaged number of action potentials elicited per stimulus) were plotted against the peak velocity of the stimulus air current. Symbols are the same as in Fig. 1. ※: statistically significant difference was confirmed between $\mathrm{BCl}$ and $\mathrm{ICl}$ animals $(\mathrm{P}<0.05)$. $\dagger$ : statistically significant difference was confirmed between $\mathrm{BCl}$ and $\mathrm{CCl}$ animals $(\mathrm{P}<0.05)$. $\mathrm{N}$ (number of animals) $=10$ for open circles. $\mathrm{N}=5$ for open squares. 


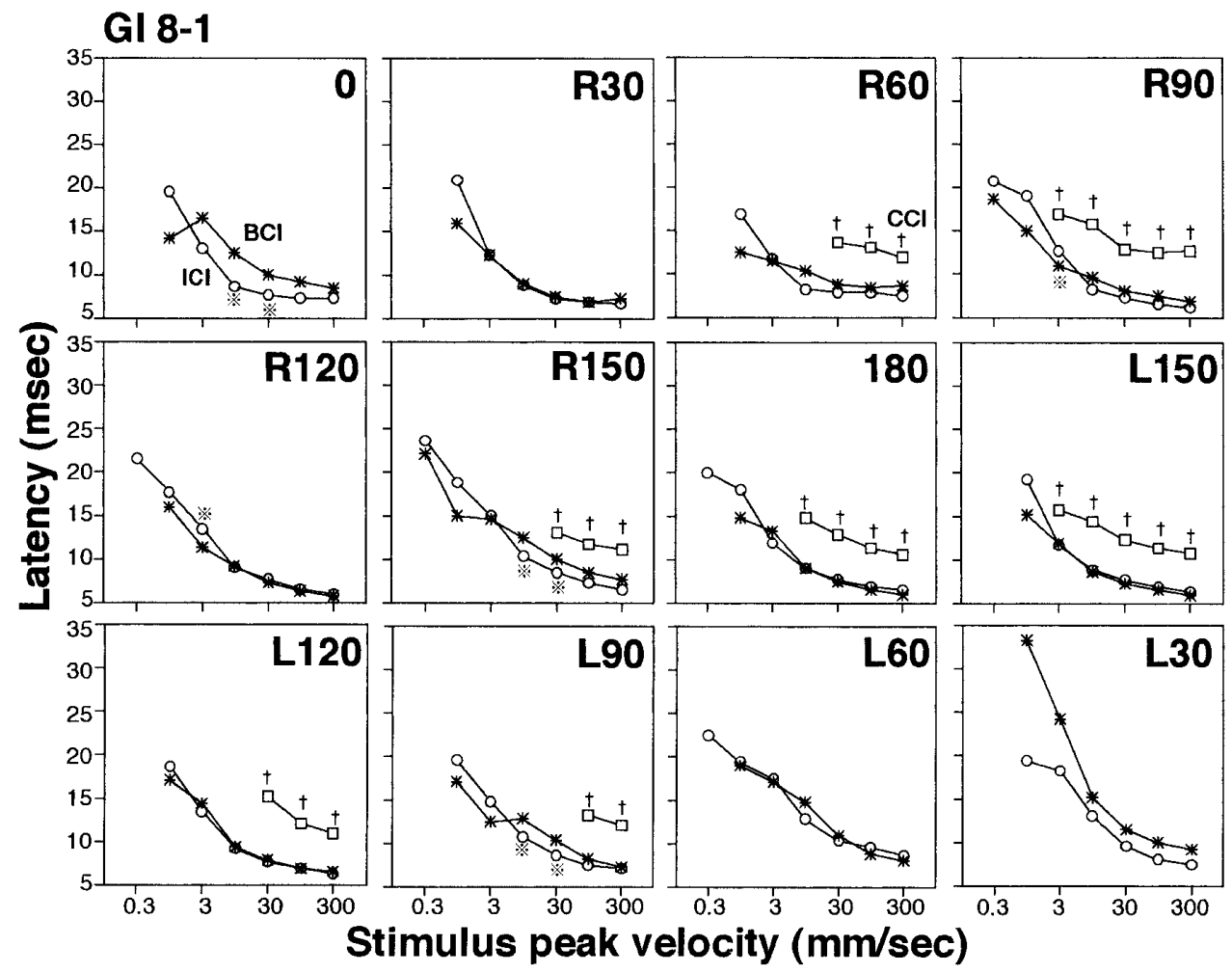

Fig. 3. Response latencies of GI 8-1. Symbols are the same as in Figs. 1 and 2. Response latencies of the Gl became shorter with the increase of stimulus velocity in all the cases. All of the response latencies in $\mathrm{CCl}$ animals were significantly longer than those in $\mathrm{BCl}$ animals. Sample numbers are the same as in Fig. 2.

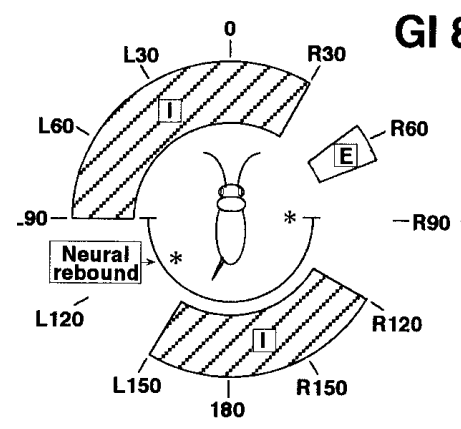

Contralateral Inputs

( $\mathrm{CCl}$ animals)
GI 8-1

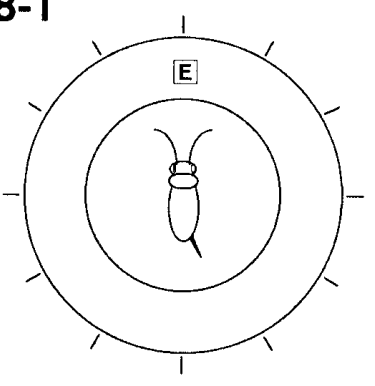

Ipsilateral Inputs (ICl animals)

Fig. 4. Stimulus directions of excitatory and inhibitory inputs on GI $8-1$ in $\mathrm{ICl}$ (ipsilateral inputs) and $\mathrm{CCl}$ (contralateral inputs) animals. Open area with "E": excitatory inputs. Hatched area with "I": inhibitory inputs. When an excitatory or inhibitory effect was ascertained in only one stimulus direction, the direction was shown a little bit wider in order to indicate the direction clearly, e.g. R60 in the left figure. Filiform hairs on the ipsilateral cercus have excitatory connection with GI 8-1 regardless of their directional sensitivities. Among filiform hairs on the contralateral cercus, only those sensitive to the air current from R60 direction have excitatory connection with the GI, and most of the other contralateral filiform hairs have inhibitory connections. Neural rebound: stimulus directions in which GI 8-1 showed responses that seemed to be caused by the rebound depolarization. Asterisk: neural depolarization was assumed only from long response latencies.

hairs sensitive to air currents from these directions have an inhibitory connection with the Gl (Fig. 4, left), the inhibition from those hairs reaches GI 8-1 faster than or almost simultaneously with the excitatory inputs from the filiform hairs on the ipsilateral cercus, and delays the Gl's membrane potential reaching threshold.

\section{Response properties of $\mathrm{Gl}$ 8-1 in $\mathrm{CCl}$ animals}

GI 8-1 in CCl animals showed very weak responses only when the stimulus air currents were applied clockwise from R60 to L90 directions (Fig. 2). It seemed somewhat paradoxical with the observed differences in the response magnitudes between $\mathrm{ICl}$ and $\mathrm{BCl}$ animals (Fig. 2) because the results suggested that contralateral filiform hairs sensitive to the air currents from R120, R150, 180, L150 and L90 had inhibitory connection with the Gl (responses to R60 air currents were caused by the excitatory inputs as mentioned before; Fig. 4). We assumed that the very weak responses (except R60) were caused by the rebound depolarization released from inhibitory hyperpolarizations (Fig. 4; Neural rebound), because latencies of those responses were significantly longer than those in $\mathrm{BCl}$ animals (longer than $10 \mathrm{msec}$, Fig. 3; see discussion).

\section{Response properties of GI 9-1 in ICl animals}

Like GI 8-1, GI 9-1 in ICl animals responded to air currents regardless of the stimulus direction (Fig. 5). It suggests that all types of filiform hairs on the ipsilateral cercus have 


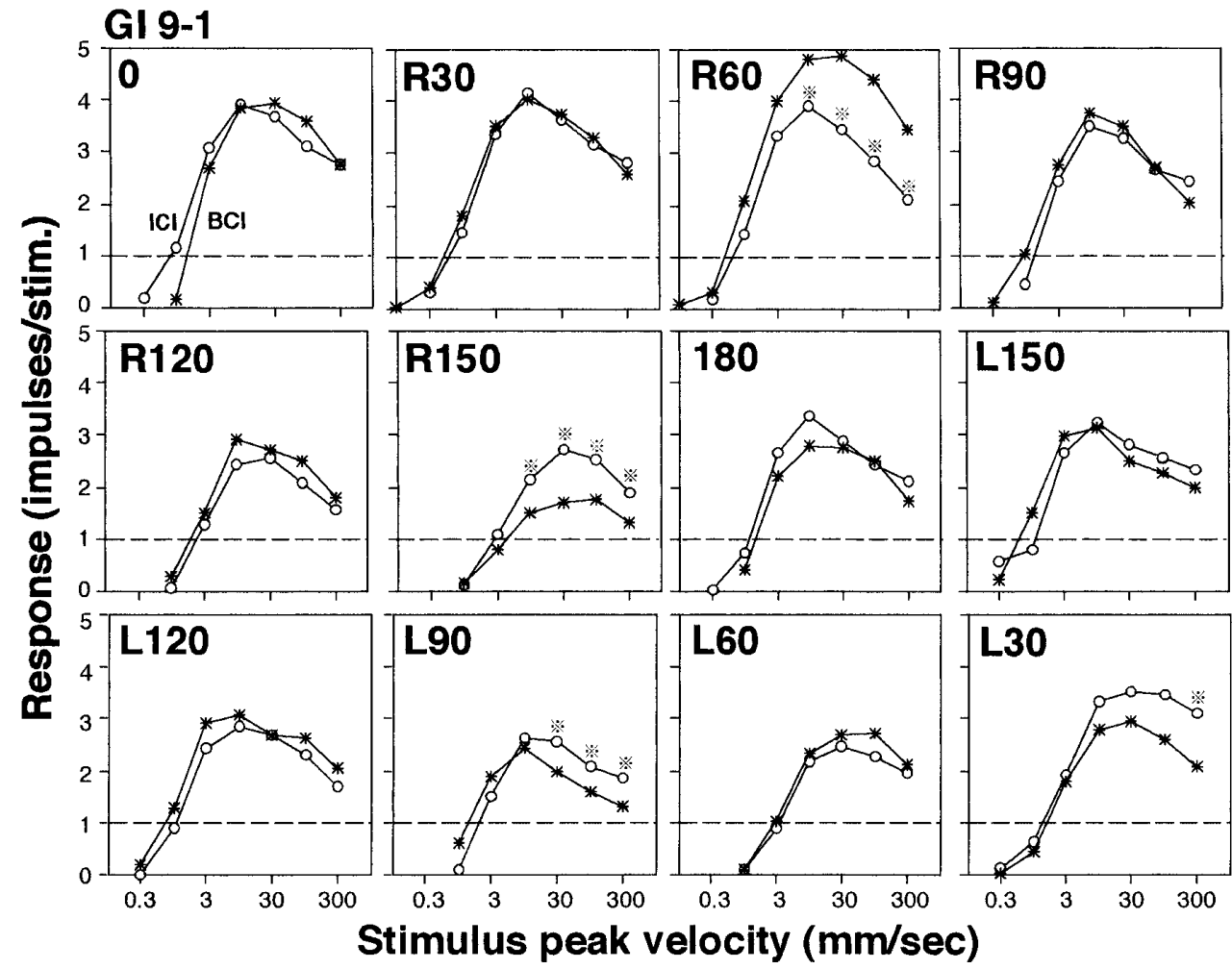

Fig. 5. Intensity-response curves of GI 9-1. Symbols are the same as in Figs. 1 and 2. In ICl animals, response magnitudes were larger than those in $\mathrm{BCl}$ animals when the air currents were applied from R150, L90 and L30 directions. On the other hand, response magnitudes in ICl animals were significantly smaller than those in $\mathrm{BCl}$ animals when the air current was applied from the R60 direction. Note that GI 9-1 in CCl animals showed no response regardless of the stimulus direction. $\mathrm{N} \geq 9$ for open circles.

excitatory connection with Gl 9-1 regardless of their directional sensitivities (Fig. 7, right). Although a receptive field of the $\mathrm{GI}$ in $\mathrm{ICl}$ animals was slightly smaller than those in $\mathrm{BCl}$ animals, those shapes were very similar to each other (Fig. 1B).

Response magnitudes of GI 9-1 in ICl animals were significantly larger than those in $\mathrm{BCl}$ animals $(P<0.05)$ when the stimulus air currents were applied from R150, L30 and L90 directions (Fig. 5). It suggests that the contralateral filiform hairs activated by such air currents have inhibitory connection with the GI (Fig. 7, left). When the air currents were applied from the R150 and L90 directions, response latencies of the $\mathrm{GI}$ in $\mathrm{ICl}$ animals were significantly shorter than those in $\mathrm{BCl}$ animals $(\mathrm{P}<0.05$; Fig. 6$)$. This suggests that the inhibitory information reaches the Gl faster than or almost simultaneously with the excitatory ones and delays the Gl's membrane potential reaching threshold.

Response latency of $\mathrm{Gl} 9-1$ in $\mathrm{BCl}$ animals became shorter with the increase of stimulus velocity in most cases, and was the shortest for air currents from mainly ipsilateralfront directions, i.e. L30, 0, R30, R60, R90 and R120 (Fig. 6). $\mathrm{In} \mathrm{ICl}$ animals, response latencies of $\mathrm{GI}$ 9-1 to the unidirectional air currents were almost the same with those in $\mathrm{BCl}$ animals regardless of the stimulus direction except for the R150 and L90 directions as mentioned above (Fig. 6).

\section{Response properties of GI 9-1 in CCl animals}

In CCl animals, no response was evoked in Gl 9-1 regardless of the direction of the stimulus air current (Fig. 5). It may suggest that no filiform hairs on the contralateral cercus have excitatory connection with the Gl, i.e. excitatory inputs seemed to be restricted from filiform hairs only on the ipsilateral cercus. However, response magnitudes of GI 9-1 in ICl animals were significantly smaller than those in $\mathrm{BCl}$ animals when the air current was applied from R60 direction (Fig. 5). It suggests that filiform hairs on the contralateral cercus activated by the R60 air current provide excitatory but subthreshold inputs to Gl 9-1 (Fig. 7, left; see discussion).

\section{Response properties of GI 9-2 in ICl animals}

Although velocity thresholds of $\mathrm{Gl}$ 9-2 in ICl animals were relatively higher than those in $\mathrm{BCl}$ animals, especially when the air currents were applied from ipsilateral-rear (R120, R150 and 180) and contralateral-front (L30, L60 and L90) directions (Fig. 1C), the Gl was still sensitive to the air currents from ipsilateral-rear directions like in $\mathrm{BCl}$ animals. Even after the unilateral cercal ablation, therefore, the preferred direction of the GI was kept constant.

GI 9-2 in $\mathrm{ICl}$ animals responded to air currents regardless of the stimulus direction (Fig. 8). It may suggest that all types of filiform hairs on the ipsilateral cercus have excitatory connection with GI 9-2 regardless of their directional sensi- 


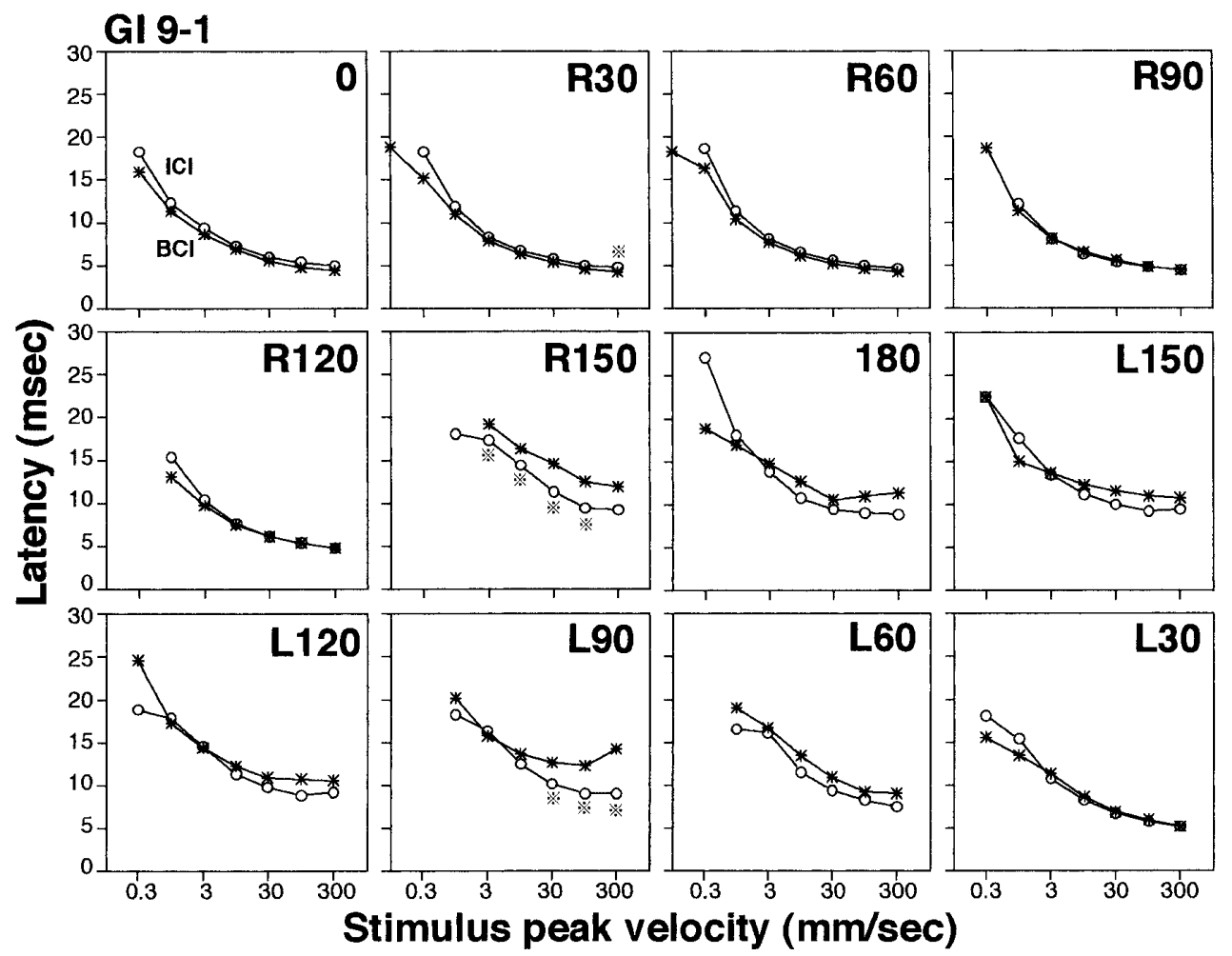

Fig. 6. Response latencies of GI 9-1. Symbols are the same as in Figs. 1 and 2. Response latencies of Gl 9-1 became shorter with the increase of stimulus velocity in both $\mathrm{BCl}$ and $\mathrm{ICl}$ animals. In ICl animals, response latencies to the air currents from R150 and $\mathrm{L} 90$ directions were shorter than those in $\mathrm{BCl}$ animals. It suggests that inhibitory information from contralateral filiform hairs sensitive to those air currents reach the Gl faster than or almost simultaneously with excitatory ones. Sample numbers are the same as in Fig. 5.

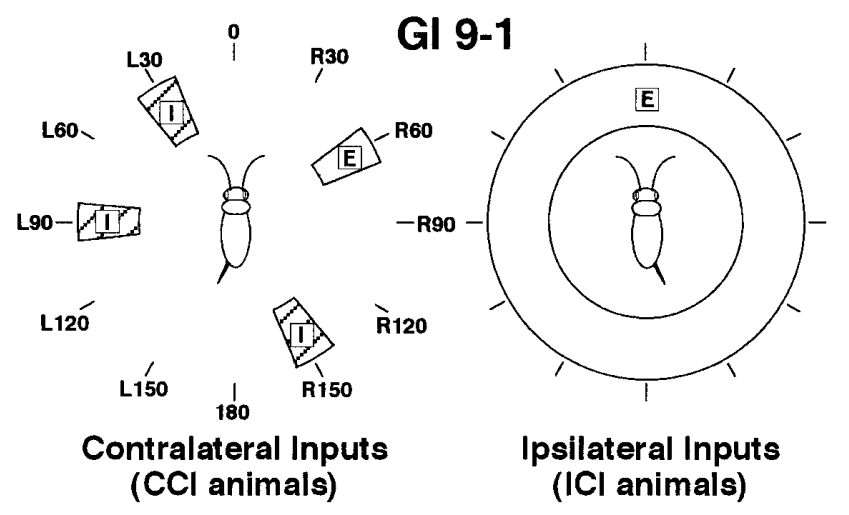

Fig. 7. Stimulus directions of excitatory and inhibitory inputs on GI 9-1. Like in Gl 8-1, filiform hairs on the ipsilateral cercus have excitatory connection with the GI regardless of their directional sensitivities. Among filiform hairs on the contralateral cercus, only those sensitive to the air current from R60 direction have excitatory connection with the GI. Filiform hairs on the contralateral cercus sensitive to the air currents from R150, L90 and L30 directions showed inhibitory connections with GI 9-1. Refer to Fig. 4 for abbreviations.

tivities. However, when the air currents were applied from L90, L60 and L30 directions, response magnitudes were relatively smaller and response latencies were considerably longer (longer than $15 \mathrm{msec}$ ) than for other directions (Figs. 8, 9). A sensory afferent of a cercal filiform hair fires when the hair is deflected in one direction. Although the afferent shows short latency responses when the stimulus air current is applied from the preferred direction, the afferent shows long latency responses which correspond to the falling phase of the unidirectional stimulus when the air current is applied from the opposite direction (Tobias and Murphey, 1979). As GI 9-2 showed short latency responses when the stimulus was applied from R90, R120 and R150 directions, ipsilateral filiform hairs sensitive to such air currents must deliver excitatory inputs to the Gl. Those afferents must evoke long latency responses to the unidirectional air current stimulus from L90, L60 and L30 directions ( $180^{\circ}$ opposite to R90, R120 and R150, respectively), and resulted in the long latency responses on Gl 9-2. We assumed that the long latency responses were caused by the rebound motion of filiform hairs (Fig. 10, right; Hair rebound; see discussion).

In the suprathreshold domain, response magnitudes of GI 9-2 in $\mathrm{ICl}$ animals were significantly larger than those in $\mathrm{BCl}$ animals when the air currents were applied from L30, 0, R30, R60, R150, 180, L150 and L120 directions (Fig. 8). It suggests that filiform hairs on the contralateral cercus sensitive to those air currents have inhibitory connection with GI 92 (Fig. 10, left). Among the cases, response latencies to the air currents from R150 and L120 directions were significantly shorter than those in $\mathrm{BCl}$ animals in most stimulus velocities $(P<0.05 ;$ Fig. 9). It suggests that the inhibition from filiform hairs on the contralateral cercus encoding those air currents 


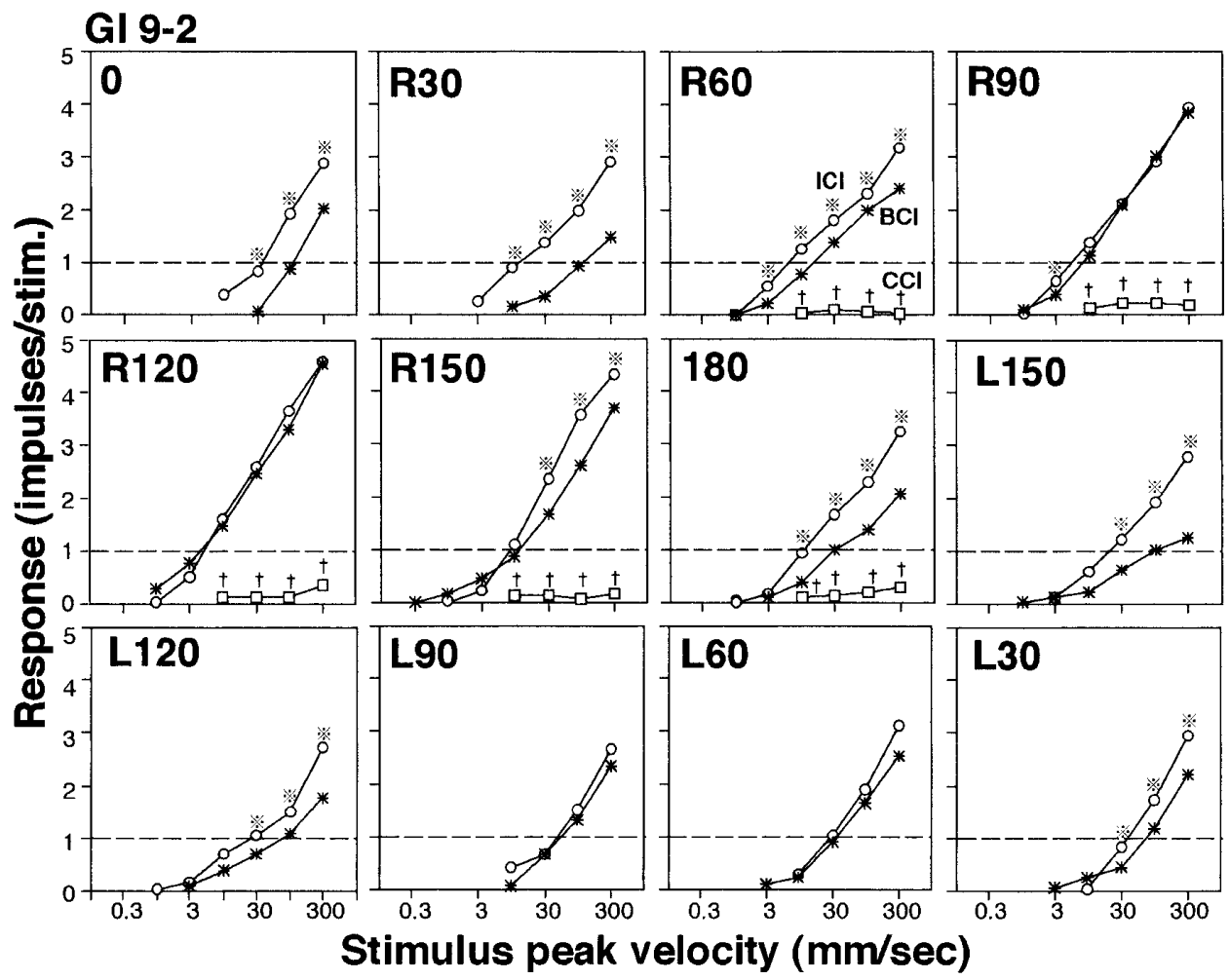

Fig. 8. Intensity-response curves of GI 9-2. Symbols are the same as in Figs. 1 and 2. Most of the response magnitudes in ICl animals were significantly larger than those in $\mathrm{BCl}$ animals. Note the very poor responses in $\mathrm{CCl}$ animals. $\mathrm{N}=10$ for open circles. $\mathrm{N}=8$ for open squares.

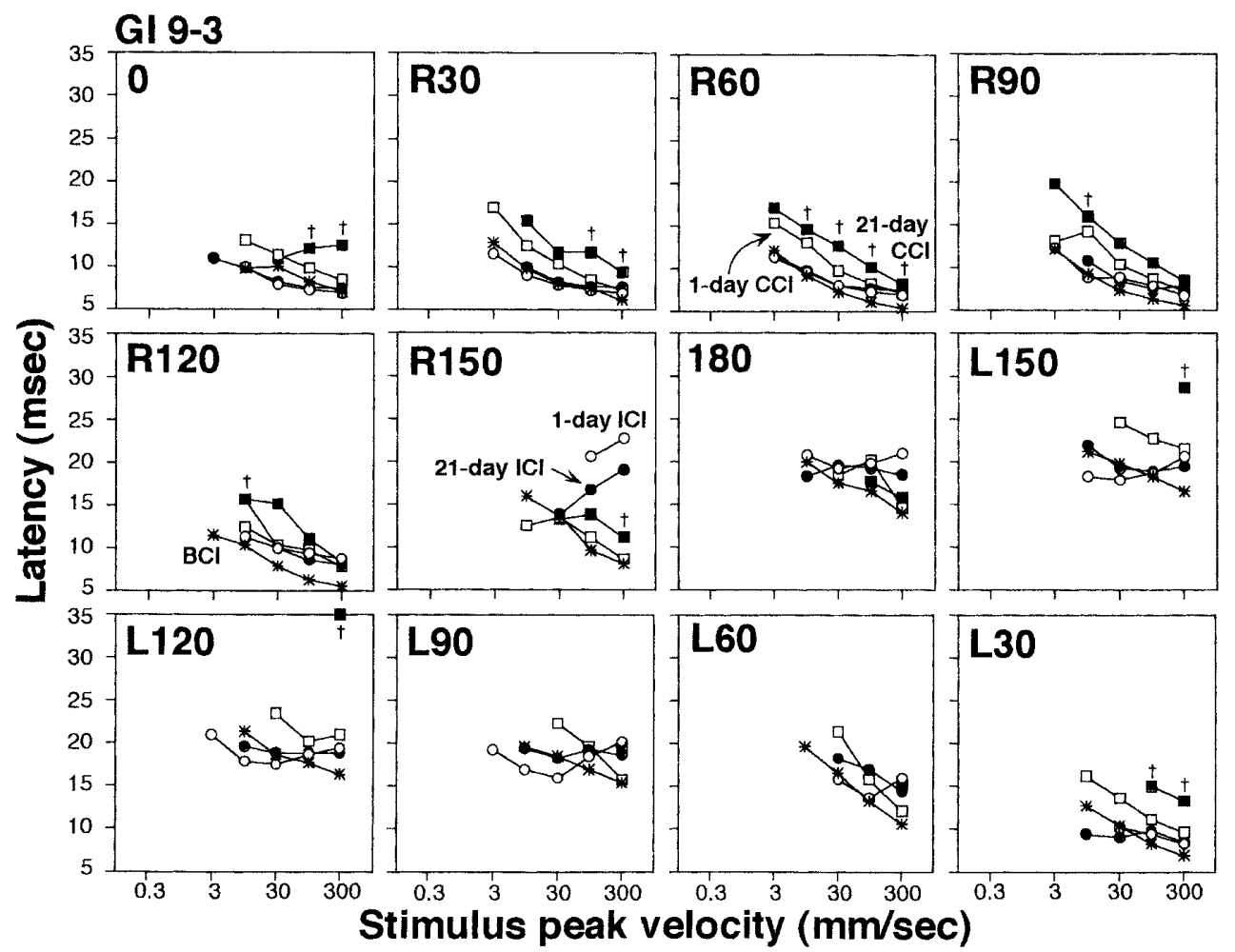

Fig. 9. Response latencies of GI 9-2. Symbols are the same as in Figs. 1 and 2. All of the response latencies in CCl animals were significantly different from those in $\mathrm{BCl}$ animals. Note the long response latencies in both $\mathrm{BCl}$ and $\mathrm{ICl}$ animals to the air currents applied from L90, L60 and L30 directions. Sample numbers are the same as in Fig. 8. 


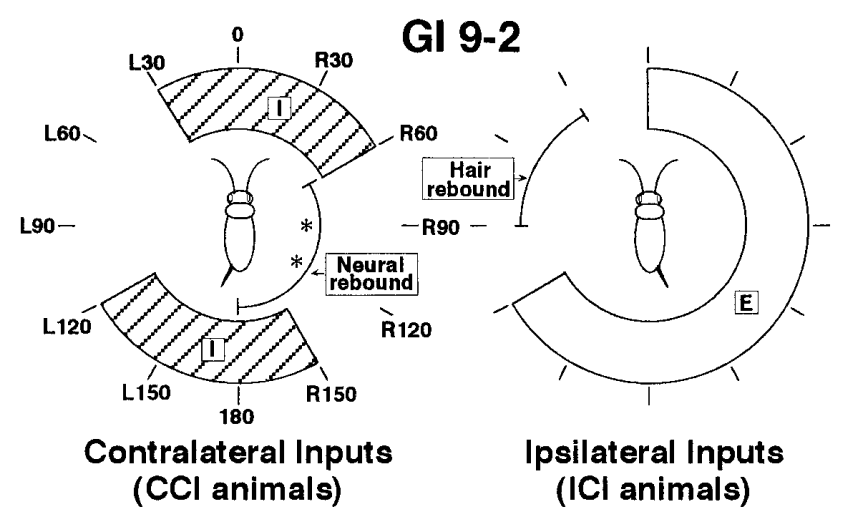

Fig. 10. Stimulus directions of excitatory and inhibitory inputs on GI 9-2. Most of the filiform hairs on the ipsilateral cercus showed excitatory connection with the Gl. On the other hand, most of the filiform hairs on the contralateral cercus showed inhibitory connection with the GI. Hair rebound: responses were supposed to be caused by the rebound motion of cercal filiform hairs. See text for details. Refer to Fig. 4 for abbreviations.

reaches the Gl earlier than or almost simultaneously with excitatory ones and delays the GI reaching threshold (see discussion).

\section{Response properties of GI 9-2 in $\mathrm{CCl}$ animals}

GI 9-2 in $\mathrm{CCl}$ animals showed responses only when the air currents were applied from R60, R90, R120, R150 and 180 directions (Fig. 8). These response magnitudes were con- siderably smaller than those in $\mathrm{BCl}$ animals. Moreover, latencies of all such responses were quite long (more than $10 \mathrm{msec}$; Fig. 9). As was suggested in $\mathrm{ICl}$ animals, filiform hairs on the contralateral cercus encoding the R60, R150 and 180 air currents have inhibitory connection with GI 9-2. Therefore, it is likely that the weak responses were caused by the rebound depolarization from the inhibition (Fig. 10, left) as was observed in GI 8-1 (see discussion).

\section{Response properties of GI 9-3 in ICl animals}

Although $\mathrm{Gl} 9-3$ in $\mathrm{ICl}$ animals showed responses to unidirectional air currents regardless of the stimulus direction, response magnitudes to the air currents applied from R150, 180, L150, L120, L90 and L60 directions were very small (Fig. 11 ), and the latencies of such responses were quite long (more than 15 msec; Fig. 12). On the other hand, response magnitudes to the air currents applied from $180^{\circ}$ opposite directions (i.e. L30, 0, R30, R60, R90 and R120, respectively) were relatively large (Fig. 11) and the latencies of those responses were relatively short (Fig. 12). Therefore, the responses to the air currents from R150, 180, L150, L120, L90 and L60 directions were likely to have been caused by the rebound motion of cercal filiform hairs because of the same reason as in GI 9-2 (Fig. 13, right).

The receptive field of $\mathrm{Gl} 9-3$ in $\mathrm{ICl}$ animals was much smaller than that in $\mathrm{BCl}$ animals (Fig. 1D). However, the most preferred direction of the Gl was remained constant even after the contralateral cercal ablation, i.e. ipsilateral-front direction.

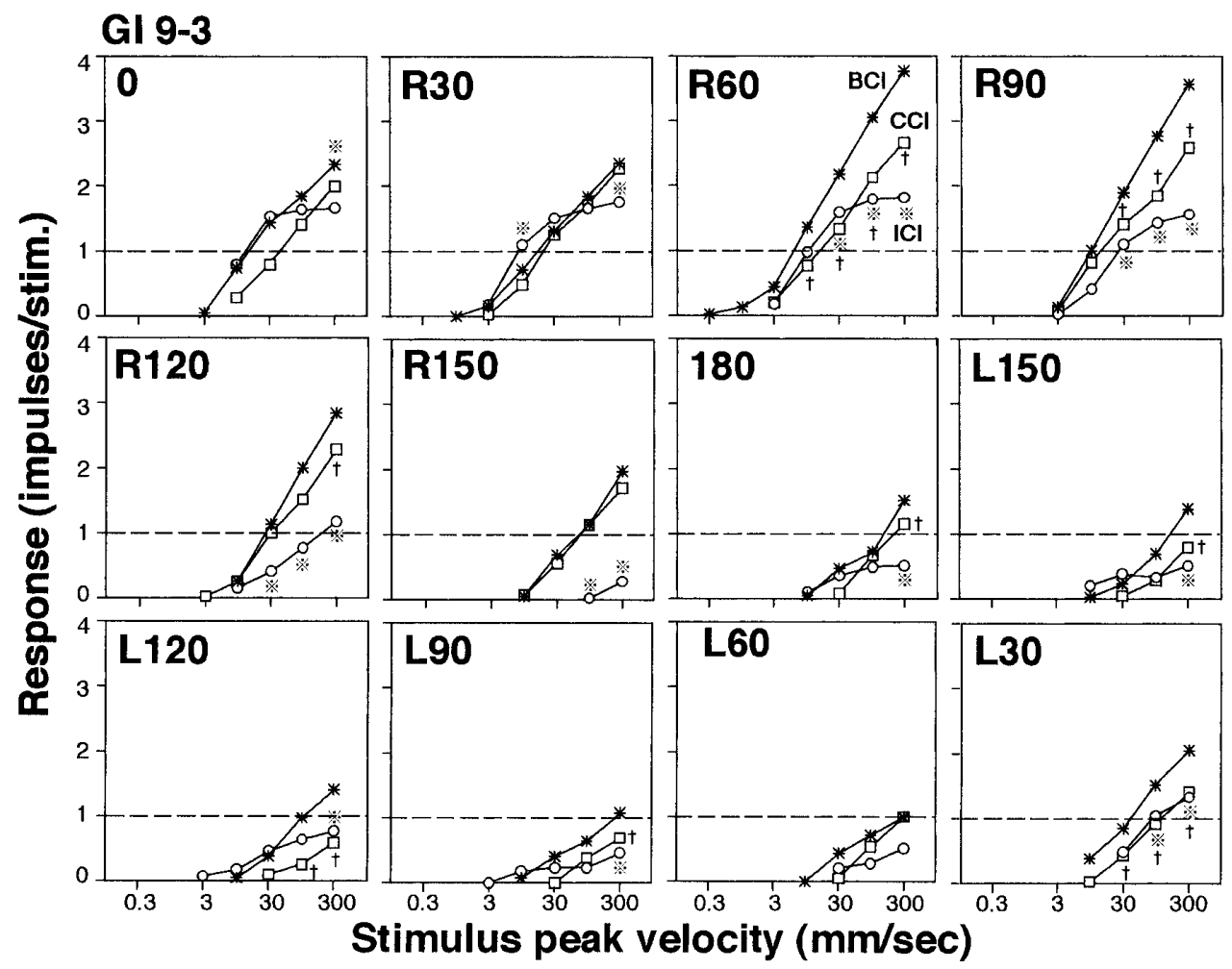

Fig. 11. Intensity-response curves of GI 9-3. Symbols are the same as in Figs. 1 and 2. Unlike other Gls, GI 9-3 in CCI animals showed relatively large response magnitudes. $\mathrm{N} \geq 10$ for all. 


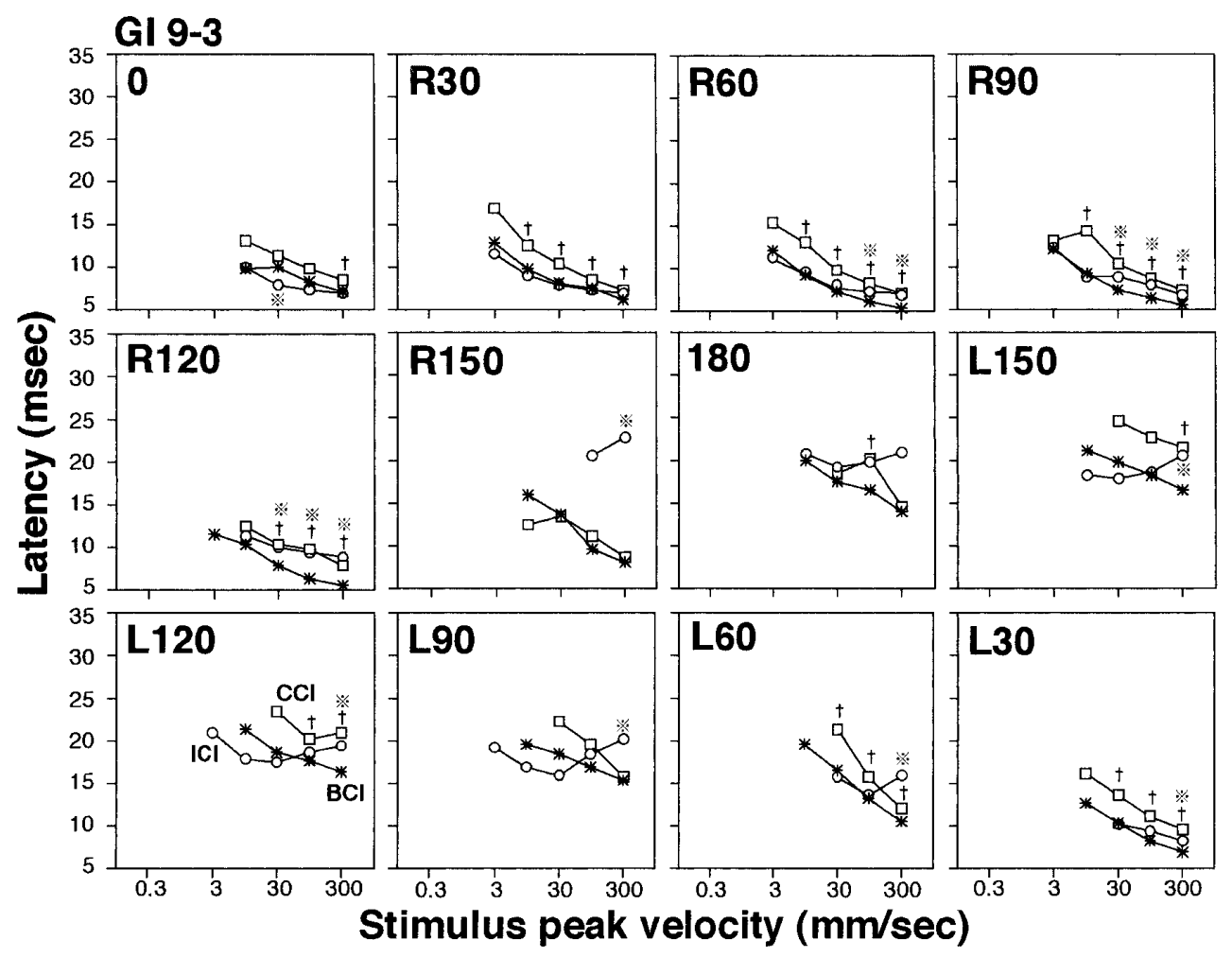

Fig. 12. Response latencies of GI 9-3. Symbols are the same as in Figs. 1 and 2. Latencies are relatively short to the air currents from the ipsilateral (right) side. Most of the directional air currents to which the Gl showed large response magnitudes (Fig. 11) caused relatively short latency responses. Sample numbers are the same as in Fig. 11.

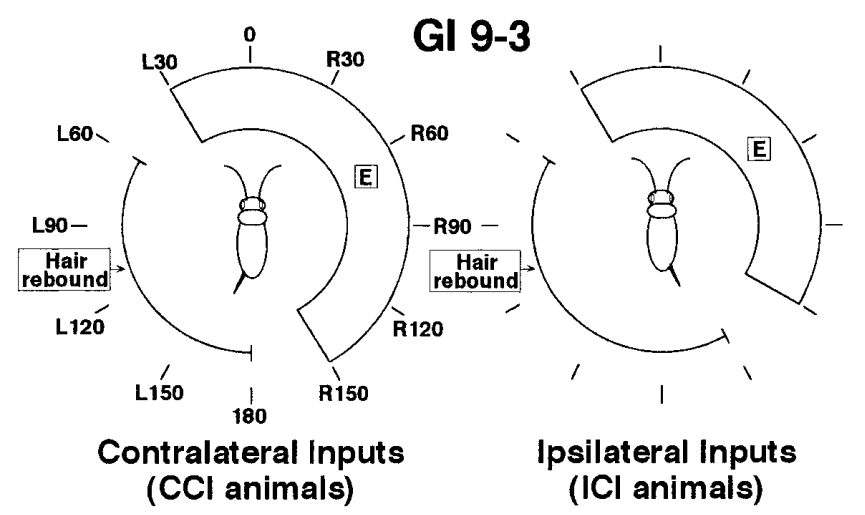

Fig. 13. Stimulus directions of excitatory inputs on GI 9-3. The directions of excitatory inputs in $\mathrm{ICl}$ and $\mathrm{CCl}$ animals are very similar to each other, i.e. the $\mathrm{Gl}$ receives almost equivalent excitatory inputs from filiform hairs on both of the cerci. No inhibitory input was confirmed in GI 9-3. Refer to Figs. 4 and 10 for abbreviations.

\section{Response properties of $\mathrm{Gl} 9-3$ in $\mathrm{CCl}$ animals}

GI 9-3 in $\mathrm{CCl}$ animals showed responses to the unidirectional air currents regardless of the stimulus direction. However, responses to the air currents from180, L150, L120, L90 and L60 directions were very small (Fig. 11). Latencies of those responses were very long, i.e. most of them were more than $15 \mathrm{msec}$ (Fig. 12). On the other hand, response magnitudes to the air currents from $180^{\circ}$ opposite directions $(0, R 30, R 60$,
$\mathrm{R} 90$ and R120, respectively) were relatively large (Fig. 11) and latencies of those responses were short (Fig. 12). These facts suggest that responses to the air currents from 180, L150, L120, L90 and L60 directions were caused by the rebound motion of cercal filiform hairs as in $\mathrm{ICl}$ animals. Therefore, excitatory inputs to Gl 9-3 in $\mathrm{CCl}$ animals are from filiform hairs sensitive to the air currents from L30, 0, R30, R60, R90, R120 and R150 directions (Fig. 13, left).

The receptive field of Gl 9-3 in $\mathrm{CCl}$ animals showed a cardioid shape but was much smaller than that in $\mathrm{BCl}$ animals (Fig. 1E). However, the preferred direction of the GI was still ipsilateral-front direction same as in $\mathrm{BCl}$ and $\mathrm{ICl}$ animals. The most preferred direction was thus kept constant even after the ipsilateral cercal ablation.

Unlike Gls 8-1 and 9-1, contralateral excitatory inputs on GI 9-3 seemed more powerful than those from ipsilateral ones (Fig. 11). Unlike other Gls (Gls 8-1, 9-1 and 9-3), any sign of inhibitory input was not confirmed on Gl 9-3 by the spike count analysis in the present study.

\section{DISCUSSION}

Faint excitatory inputs for sharpening the directional characteristics

We showed that some Gls received very faint subthreshold excitatory inputs from cercal filiform hairs sensitive to the air currents from particular directions. For example, an air 
current from R60 direction elicited significantly larger responses on $\mathrm{Gl} 8-1$ in $\mathrm{BCl}$ animals than those observed in $\mathrm{ICl}$ animals (Fig. 2). Such a difference must be due to the strong excitatory inputs from contralateral cercal filiform hairs sensitive to the R60 air current. However, the same air current given to $\mathrm{CCl}$ animals elicited only a few responses on the Gl. This suggests that the contralateral excitatory inputs are not strong enough to elicit a neural response on GI 8-1 alone, but can make facilitative responses on the GI by working with the ipsilateral excitatory inputs. Similar weak excitatory inputs were also observed in GI 9-1. Although a response to R60 air currents was not observed in $\mathrm{CCl}$ animals, response magnitudes of the $\mathrm{Gl}$ in $\mathrm{BCl}$ animals were significantly larger than those observed in $\mathrm{ICl}$ animals (Fig. 5). This also shows that contralateral filiform hairs encoding the R60 air current provide excitatory inputs to the GI for the facilitative responses. The facilitative responses caused by the weak contralateral inputs on both Gls 8-1 and 9-1 must have a significant role in sharpening the directional characteristic of these Gls.

\section{Rebound motion of cercal filiform hairs}

In addition to the simple excitatory and inhibitory connections, the rebound motion of cercal filiform hairs also have some role for making the neural responses of Gls 9-2 and 93 to an air current stimulus. As mentioned in the results, it has been reported that a sensory neuron of a filiform hair which responded to the rising phase of a unidirectional air-puff stimulus responded to the falling phase when the stimulus was delivered from $180^{\circ}$ opposite directions (Tobias and Murphey, 1979). The authors of the previous study presumed that the response to the falling phase reflected the hair's return to rest position. However, we assumed that the response was due to the excess rebound motion of the hair after returning to the resting position because the structure of the basal part of a filiform hair indicated that the sensory neuron was activated only when the hair shaft was bent to one particular direction (Gnatzy and Tautz, 1980). As cricket filiform hairs show damped free oscillation after they are bent (Tautz, 1977; Shimozawa and Kanou, 1984b), a deflection angle of the filiform hairs during the excess rebound motion must be considerably smaller than that during the initial motion in rising phase. The small response magnitudes of Gls 9-2 and 9-3 during the rebound motion of filiform hairs must be due to such small deflection angles. As the rebound motion of a hair occurs after the motion in rising phase, a response latency of the sensory afferents to the rebound motion must be longer than that in the rising phase. This must be the reason why the response latencies of the Gls 9-2 and 9-3 were long in such conditions.

\section{Neural rebound}

Gls 8-1 and 9-2 in $\mathrm{CCl}$ animals showed very poor responses with appreciably long latencies (Figs. 2, 3, 8, 9) when the air currents were applied from particular directions (marked as "Neural rebound" in Figs. 4, 10). Those were somewhat paradoxical with the results obtained from the comparison of the response magnitudes between $\mathrm{BCl}$ and $\mathrm{ICl}$ animals, because such air currents applied to the contralateral cercus showed inhibitory or almost no effect on the Gls' responses (Figs. 4, 10). Evidently, those responses were not caused by the rebound motion of cercal filiform hairs because most of the filiform hairs sensitive to the air currents from $180^{\circ}$ opposite to those directions showed inhibitory connections with the Gls (Figs. 4, 10). We hypothesized that those responses were caused by the rebound depolarization due to the release from an inhibitory hyperpolarization (neural rebound). The long latencies of the responses can be well explained by the hypothesis because the rebound depolarization, if any, occurs after a certain period of hyperpolarization caused by the air current stimulus. The poorness of the responses might also be explained by the hypothesis if the amplitude of rebound depolarization was smaller than the usual depolarization caused by the excitatory inputs. Although the hypothesis is based only on the circumstantial evidences, it is the most plausible interpretation for the paradoxical observations.

Significance of the neural responses evoked by the rebound depolarization has been suggested in some animals. In the central nervous system of the echolocating mustached bats (Pteronotus parnellii), for example, FM-FM neurons are created for encoding target range information (O'Neill and Suga, 1979). Such neurons show facilitative responses when an orientation sound (pulse) and a reflecting echo are presented with a particular time delay. That means the facilitation occurs when a long latency response to a pulse reaches an FM-FM neuron simultaneously with a short latency response to an echo. It has been thought that the long latency response to a pulse is formed by the rebound depolarization from inhibitions (Suga, 1990). Although we could not find any biological meaning of the rebound depolarization evoked responses in the cricket cercal sensory system, such responses must have some role for the processing of the air current information.

\section{Polysynaptic inhibitory and excitatory neural pathways}

As primary afferents in vertebrates or arthropods cannot mediate inhibition directly (Calabrese, 1976), inhibitory information from filiform hairs on the contralateral cercus to Gls 81, 9-1 and 9-2 must be relayed by inhibitory interneurons. Since directional characteristics of inhibition are different from GI to GI, different types and/or numbers of local interneurons in the cricket cercal system (Kobashi and Yamaguchi, 1984; Baba et al., 1995) must be recruited for mediating inhibitory information.

In addition to the polysynaptical inhibitory pathways, some of the excitatory information must also be polysynaptically relayed. For example, when the air currents were applied from R150 and L90 directions, response magnitudes of GI 9-1 became larger and response latencies of the Gl became shorter than those in $\mathrm{BCl}$ animals after the ablation of the contralateral cercus (Fig. 6). Similar changes have been observed in GI 9-2 when the air currents were applied from R150 and L120 directions (Fig. 9). These facts suggest that the fili- 
form hairs on the contralateral cercus sensitive to those air currents have inhibitory connection with each Gl. Moreover, the inhibitory information must reach the Gls faster than or almost simultaneously with excitatory ones and affect the membrane potentials of the Gls because the inhibitory information apparently delays the Gls' membrane potential reaching a firing level. As inhibitory information must be relayed by at least one local interneuron as mentioned above, excitatory inputs to the Gls must also be polysynaptically relayed. The polysynaptical excitatory neural pathways in the cricket cercal system have also been suggested in the previous study dealing with local interneurons (Baba et al., 1995).

\section{Consistency of GIs' preferred directions after the unilat- eral cercal ablations}

In Gls 8-1, 9-1 and 9-2, excitatory inputs from contralateral cercal filfiorm hairs were considerably limited. Therefore, the receptive fields of the Gls were ascertained only in $\mathrm{ICl}$ animals. In GI 8-1, the receptive field of $\mathrm{ICl}$ animals was almost identical with that in $\mathrm{BCl}$ animals (Fig. 1A). In Gls 9-1 and 9-2, most velocity thresholds in $\mathrm{ICl}$ animals were different from those in $\mathrm{BCl}$ animals. However, the preferred direction of each $\mathrm{Gl}$ was still consistent with that in $\mathrm{BCl}$ animals, i.e. ipsilateral-front and contralateral-rear directions for GI 91 and ipsilatral-rear direction for GI 9-2 (Fig. 1B, C). GI 9-3 received excitatory inputs from filiform hairs on both ipsilateral and contralateral cerci. Therefore, velocity thresholds of GI 9-3 in unilaterally cercal ablated animals were significantly higher than those in $\mathrm{BCl}$ animals. However, in spite of the shrinkage of the receptive fields, the most sensitive direction of $\mathrm{Gl}$ 9-3 in the treated animals (ICl or $\mathrm{CCl}$ ) was still ipsilateral-front directions as in $\mathrm{BCl}$ animals (Fig. 1D, E). Thus, the preferred direction (the most sensitive directions) of each GI was considerably well maintained even after a unilateral cercal ablation. We have observed that crickets still showed directional escape to an air current stimulus even after the unilateral cercal ablation, though the accuracy became worse to some extent (Kanou et al., in preparation). The consistency of Gls' directional properties must ensure the crickets keep the direction of the escape constant even after experiencing damages on cercal filiform hairs.

\section{ACKNOWLEDGMENT}

The authors are grateful to Dr. J. B. Kershaw, Akita Laboratory, Japan Science and Technology Corporation, for his critical reading and English proof of the manuscript. This work was partially supported by a Grant-in-Aid for Scientific Research 07640903 from the Japanese Ministry of Education, Science, Sports and Culture to M. K.

\section{REFERENCES}

Baba Y, Hirota K, Shimozawa T, Yamaguchi T (1995) Differing afferent connections of spiking and nonspiking wind-sensitive local interneurons in the terminal abdominal ganglion of the cricket Gryllus bimaculatus. J Comp Physiol A 176: 17-30

Bacon JP, Murphey RK (1984) Receptive field of cricket giant interneurons are related to their dendritic structure. J Physiol 352:
$601-623$

Bentley D (1975) Single gene cricket mutations: Effects on behavior, sensilla, sensory neurons, and identified interneurons. Science 187: 760-764

Bodnar DA, Miller JP, Jacobs GA (1991) Anatomy and physiology of identified wind-sensitive local interneurons in the cricket cercal sensory system. J Comp Physiol A 168: 553-564

Calabrese RL (1976) Crayfish mechanoreceptive interneurons: II. Bilateral interactions and inhibition. J Comp Physiol A 105: 103114

Edwards JS, Palka J (1974) The cerci and abdominal giant fibers of the house cricket, Acheta domesticus. I. Anatomy and physiology of normal adults. Proc R Soc Lond B 185: 83-103

Gnatzy W, Tautz J (1980) Ultrastructure and mechanical properties of an insect mechanoreceptor: Stimulus-transmitting structure and sensory apparatus of the cercal filiform hairs of Gryllus. Cell Tissue Res 213: 441-463

Gras H, Hörner M (1992) Wind-evoked escape running of the cricket Gryllus bimaculatus. I. Behavioral analysis. J Exp Biol 171: 189214

Jacobs G, Miller JP, Murphey RK (1986) Integrative mechanisms controlling directional sensitivity of an identified sensory interneuron. J Neurosci 6: 2298-2311

Kanou M (1991) Threshold and directional sensitivity of air-current sensitive giant interneuron of a cricket. Experientia 47: 447-448

Kanou M (1996) Directionality of cricket giant interneurons to escape eliciting unidirectional air-current. Zool Sci 13: 35-46

Kanou M, Shimozawa T (1984) A threshold analysis of cricket cercal interneurons by an alternating air current stimulus. J Comp Physiol A 154: 357-365

Kanou M, Shimozawa T (1985) Responses of cricket leg motoneurons to air-current stimuli: Velocity dependent inhibition and acceleration dependent excitation. Zool Sci 2: 629-639

Kanou M, Osawa T, Shimozawa T (1988) Ecdysial growth of the filiform hairs and sensitivity of the cercal sensory system of the cricket Gryllus bimaculatus. J Comp Physiol A 162: 573-579

Kanou M, Osawa T, Shimozawa T (1989) Mechanical polarization in the air-current sensory hair of a cricket. Experientia 45: 10821083

Kanou M, Ohshima M, Inoue J (1995) Analysis of air-current evoked escape behavior of the cricket. Zool Sci 12 (Suppl): 100 (Proceedings of the 66th annual meeting of the Zoological Society of Japan)

Kobashi M, Yamaguchi T (1984) Local non-spiking interneurons in the cercus-to-giant interneuron system of cricket. Naturwissenschaften 71: 154

Landolfa MA, Jacobs GA (1995) Direction sensitivity of the filiform hair population of the cricket cercal system. J Comp Physiol A 177: $759-766$

Levine RB, Murphey RK (1980) Pre- and postsynaptic inhibition of identified giant interneurons in the cricket (Acheta domesticus). J Comp Physiol A 135: 269-282

Matsuura T, Kanou M (1998) Functional recovery of cricket giant interneurons after cercal ablations. Zool Sci 15: 195-204

O'Neill WE, Suga N (1979) Target range-sensitive neurons in the auditory cortex of the mustached bat. Science 203: 69-73

Shepherd D, Kämper G, Murphey RK (1988) The synaptic origins of receptive field properties in the cricket cercal sensory system. $J$ Comp Physiol A 162: 1-11

Shimozawa T, Kanou M (1984a) Varieties of filiform hairs: range fractionation by sensory afferents and cercal interneurons of a cricket. J Comp Physiol A 155: 485-493

Shimozawa T, Kanou M (1984b) The aerodynamics and sensory physiology of range fractionation in the cercal filiform sensilla of the cricket Gryllus bimaculatus. J Comp Physiol A 155: 495-505

Suga N (1990) Computation of velocity and range in the bat auditory system for echo location. In "Computational Neuroscience" Ed 
by Schwartz EL, MIT Press, Chapter 17, 213-231

Tautz J (1977) Reception of medium vibration by thoracal hairs of caterpillars of Barathra brassicae L. (Lepidoptera, Noctuidae). J Comp Physiol A 118: 13-31

Tobias M, Murphey RK (1979) The response of cercal receptors and identified interneurons in the cricket (Acheta domesticus) to air- streams. J Comp Physiol A 129: 51-59

Walthall WW, Murphey RK (1986) Positional information, competition, and the cercal sensory system of crickets. Develop Biol 113: $182-200$

(Received May 22, 1997 / Accepted January 29, 1998) 